\title{
ASTHMA
}

\section{Risk factors associated with the presence of irreversible airflow limitation and reduced transfer coefficient in patients with asthma after 26 years of follow up}

\author{
J M Vonk, H Jongepier, C I M Panhuysen, J P Schouten, E R Bleecker, D S Postma
}

Thorax 2003;58:322-327

See end of article for authors' affiliations

Correspondence to: Professor D S Postma Department of Pulmonology, University Hospital, Hanzeplein 1 . 9713 GZ Groningen, The Netherlands;

d.s.postma@int.azg.nl

Revised version received 7 December 2002 Accepted for publication 16 December 2002

\begin{abstract}
Background: Childhood asthma is generally believed to be a disorder with a good prognosis. However, some asthmatics develop irreversible airway obstruction, probably as a result of airway remodelling.

Methods: After 21-33 years, 228 adults (aged 13-44 years at baseline) with a history of asthma were re-examined to assess risk factors for the development of irreversible airway obstruction (IAO, forced expiratory volume in 1 second $\left(\mathrm{FEV}_{1}\right)<80 \%$ predicted and reversibility $<9 \%$ predicted) and a reduced postbronchodilator transfer coefficient (carbon monoxide transfer factor/alveolar volume, $<80 \%$ predicted), both characteristics of COPD.

Results: At follow up, $41 \%$ did not have airway obstruction (NAO), 43\% had reversible airway obstruction (RAO), and $16 \%$ had IAO; $23 \%$ had a reduced transfer coefficient. Patients with RAO had asthma-like characteristics (wheezing, asthma attacks, bronchial hyperresponsiveness (BHR)) while patients with IAO had COPD-like symptoms (cough, phlegm, dyspnoea) at follow up. The development of IAO is determined by a lower FEV ${ }_{1}$, less reversibility of airway obstruction and, surprisingly, less severe BHR at initial screening. Eighty percent of the patients with asthma who used anti-inflammatory medication still had airway obstruction, but IAO developed less frequently. Smoking was associated with a reduced transfer coefficient but not with the development of IAO. Female sex was associated with a reduced transfer coefficient, whereas corticosteroid use was not.

Conclusions: Although IAO and a low transfer coefficient are both characteristics of COPD, they represent distinct entities in adult asthmatics in terms of symptomatology, aetiology, and probably in therapeutic approaches and disease prevention.
\end{abstract}

$\mathrm{C}$ hildhood asthma is generally believed to be a disorder with a good prognosis. When only asthma symptoms are taken into account, almost $50 \%$ of children with asthma will be asymptomatic when reaching adulthood..$^{1-4}$ However, many of these asymptomatic adults with a history of childhood asthma have persistent bronchial hyperresponsiveness, with or without airway obstruction. ${ }^{25}$ Furthermore, a considerable relapse rate has been reported in subjects thought to have outgrown their asthma. ${ }^{6}$ Prospective studies comparing adult asthmatics with non-asthmatics have shown a faster decline in forced expiratory volume in 1 second $\left(\mathrm{FEV}_{1}\right)$ in those with asthma ${ }^{7-9}$ which may lead to persistent and progressive airway obstruction. ${ }^{10}$

Although several risk factors for ongoing disease activity from childhood to adulthood are reported in the literature, only a few prospective studies have been published identifying risk factors for the development of irreversible airway obstruction (IAO) in patients with asthma. Ulrik and Backer ${ }^{11}$ conducted a 10 -year follow up study in 92 non-smoking adult asthmatics and found that a higher degree of bronchodilator reversibility at enrolment and long term treatment with oral corticosteroids were associated with IAO at follow up. Other studies have shown that the duration of asthma and the severity of the disease are associated with IAO. ${ }^{12-14}$ IAO is compatible with a diagnosis of chronic obstructive pulmonary disease (COPD). Since previous studies have shown that it may also occur in patients with chronic asthma, other patient characteristics are needed to separate asthma from COPD if irreversibility exists in older individuals. One characteristic that may separate asthma from COPD is a reduced transfer coefficient ( $\mathrm{KCO}$ ) which has been associated with the presence of emphysema. ${ }^{15}$
In the present study a cohort of patients with asthma treated between 1962 and 1970 were restudied after a follow up period of 21-33 years with the aim of identifying risk factors for the development of IAO and reduced Kco.

\section{METHODS}

\section{Study design}

Two hundred and twenty eight patients with asthma admitted to the asthma clinic at Beatrixoord Hospital in Haren, The Netherlands between 1962 and 1970 (visit 1) were reexamined between 1991 and 1998 at the same clinic (visit 2). Inclusion criteria at visit 1 were: age $<45$ years, a $20 \%$ fall in $\mathrm{FEV}_{1}$ during a histamine challenge test, no IAO, and clinical symptoms of asthma according to current ATS criteria. ${ }^{16}{ }^{17}$ Exclusion criteria were the presence of specific respiratory disease (such as cystic fibrosis or tuberculosis) or any other serious interfering disease. At both visits the patients had to be in a stable condition without an exacerbation in the previous 6 weeks.

The study was approved by the medical ethics committee of the University Hospital Groningen and participants gave their informed consent.

During both visits a questionnaire on respiratory symptoms, lung function test, histamine challenge test, and allergen skin tests were performed. ${ }^{2}$ The transfer coefficient (KCO, carbon monoxide transfer factor (TLCO)/alveolar volume (VA)) was assessed at visit 2 only. Tuco was measured by the single breath method (Masterlab Transfer System; Jaeger, Würzberg, Germany), corrected for the haemoglobin level in peripheral blood and divided by VA. 
Table 1 Characteristics of non-participating and participating patients $(n=430)$.

\begin{tabular}{|c|c|c|c|}
\hline & \multirow{2}{*}{$\begin{array}{l}\text { Non-participants } \\
\text { Visit } 1 \\
(1962-70)\end{array}$} & \multicolumn{2}{|l|}{ Participants } \\
\hline & & $\begin{array}{l}\text { Visit 1 } \\
\text { (1962-70) }\end{array}$ & $\begin{array}{l}\text { Visit } 2 \\
\text { (1991-8) }\end{array}$ \\
\hline$n$ & 202 & 228 & 228 \\
\hline Median (range) time to follow up (years) & - & - & $26(21-33)$ \\
\hline Median (range) age (years) & $28(13-44)$ & $23(13-44)^{*}$ & $49.5(35-74)$ \\
\hline Sex (\% male) & 62.4 & 57.9 & - \\
\hline Median (range) age of onset of asthma (years) & $4(0-42)$ & $4(0-39)$ & - \\
\hline Median (range) untreated period (years) & $11(0-40)$ & $14(0-42)$ & - \\
\hline Smoking $(\%)$ & 52.5 & $36.8 *$ & 26.8 \\
\hline$\geqslant 1$ positive skin test (\%) & 86.1 & $94.3^{*}$ & 82.5 \\
\hline Geometric mean (SD) lgE (IU) & No data & No data & $87.3(4.1)$ \\
\hline Geometric mean (SD) slope BHR & $6.2(3.4)$ & $7.1(3.4)$ & $3.9(4.7)$ \\
\hline $\mathrm{BHR} \leqslant 32 \mathrm{mg} / \mathrm{ml}(\%)$ & 100 & 100 & $84.3^{1}$ \\
\hline $\mathrm{BHR} \leqslant 4 \mathrm{mg} / \mathrm{ml}(\%)$ & 50.5 & 55.7 & 52.0 \\
\hline Mean (SD) prebronchodilator FEV $(\%$ pred) & $62.1(23.1)$ & $62.8(23.1)$ & $71.1(23.5)$ \\
\hline Mean (SD) postbronchodilator FEV $1 \%$ pred) & $85.4(22.2)$ & $88.0(20.6)$ & $83.6(22.2)$ \\
\hline Mean (SD) FEV ${ }_{1}$ reversibility (\% pred) & $23.3(11.0)$ & 25.2 (12.9) & $12.5(7.5)$ \\
\hline $\mathrm{FEV}_{1}$ reversibility $\geqslant 9 \%$ predicted $(\%)$ & 96.0 & 95.2 & 63.1 \\
\hline
\end{tabular}

\section{Statistical analysis}

IAO was defined as a prebronchodilator $\mathrm{FEV}_{1}$ of $<80 \%$ predicted, improving by $<9 \%$ predicted after administration of $800 \mu \mathrm{g}$ salbutamol (albuterol). Reversible airway obstruction (RAO) was defined as a prebronchodilator $\mathrm{FEV}_{1}$ of $<80 \%$ predicted, improving by $\geqslant 9 \%$ predicted after administration of salbutamol. No airway obstruction (NAO) was defined as a prebronchodilator $\mathrm{FEV}_{1}$ of $\geqslant 80 \%$ predicted. Reduced Kco was defined as a postbronchodilator TLCO/VA of $<80 \%$ predicted. The untreated period from the onset of symptoms was defined as the time between the onset of asthma symptoms as reported in the questionnaire at visit 1 and the first treatment of the disease at Beatrixoord (visit 1). Smoking was defined as life time smoking in pack years (number of years a subject smoked 20 cigarettes/day). A subject was considered allergic when at least one positive $(\geqslant 5 \mathrm{~mm})$ allergen skin test was present.

A comparison of the characteristics of patients with NAO, RAO and IAO was first performed using one-way analysis of variance (for normal distributions), the Kruskal-Wallis test (for non-normal distributions), or a $\chi^{2}$ test (for categorical variables). If these tests indicated a difference between the three groups, group-by-group comparisons were performed with a Student's $t$ test, Mann-Whitney $U$ test, or $\chi^{2}$ test as

Table 2 Characteristics of subjects stratified by airway obstruction and reversibility at visit 2 ( $n=225$ )

\begin{tabular}{|c|c|c|c|}
\hline & $\begin{array}{l}\text { No airway } \\
\text { obstruction (NAO) }\end{array}$ & $\begin{array}{l}\text { Reversible airway } \\
\text { obstruction (RAO) }\end{array}$ & $\begin{array}{l}\text { Irreversible airway } \\
\text { obstruction (IAO) }\end{array}$ \\
\hline $\mathrm{n}$ & 93 & 97 & 35 \\
\hline Median (range) age at visit 1 (years) & $19(13-39)^{*} \dagger$ & $27(13-44)^{*}$ & $27(13-44) \dagger$ \\
\hline Sex (\% male) & 53.8 & 61.9 & 60.0 \\
\hline Median (range) age of onset of asthma (years) & $5(0-36)$ & $4(0-37)$ & $4(0-39)$ \\
\hline Median (range) untreated period (years) & $12(0-36)^{*} \dagger$ & $15(0-42)^{*}$ & $19(0-42) \dagger$ \\
\hline Smoking visit 1 , non/ex/current (\%) & $54.8 / 11.8 / 33.3$ & $54.6 / 7.2 / 38.1$ & $54.3 / 2.9 / 42.9$ \\
\hline Smoking visit 2 , non/ex/current (\%) & $38.7 / 30.1 / 31.2$ & $42.3 / 35.1 / 22.7$ & $40.0 / 31.4 / 28.6$ \\
\hline Median (range) pack years smoking at visit 2 & $3.0(0-37)$ & $2.5(0-80)$ & $4.5(0-56)$ \\
\hline$\geqslant 1$ positive skin test at visit $1(\%)$ & 96.8 & 92.8 & 91.4 \\
\hline$\geqslant 1$ positive skin test at visit $2(\%)$ & $89.2 \dagger$ & 80.4 & $74.3 \dagger$ \\
\hline Geometric mean (SD) lgE at visit 2 (IU) & $89.1(3.5)$ & $97.7(4.5)$ & $67.6(4.7)$ \\
\hline Geometric mean (SD) slope BHR at visit 1 & $5.4(3.3)^{*}$ & $9.7(3.3)^{*}$ & $6.4(3.8)$ \\
\hline Geometric mean (SD) slope BHR at visit 2 & $1.8(4.6)^{*} \dagger$ & $9.8(3.2)^{*} \ddagger$ & $3.9(3.4) \dagger \ddagger$ \\
\hline $\mathrm{BHR} \leqslant 4 \mathrm{mg} / \mathrm{ml}$ at visit 1 (\%) & $47.3^{*}$ & $64.9^{*}$ & 51.4 \\
\hline $\mathrm{BHR} \leqslant 32 \mathrm{mg} / \mathrm{ml}$ at visit $2(\%)$ & $69.9 * \dagger$ & $98.7^{*}$ & $92.9 \dagger$ \\
\hline $\mathrm{BHR} \leqslant 4 \mathrm{mg} / \mathrm{ml}$ at visit $2(\%)$ & $31.2^{*}$ & $80.3^{*} \ddagger$ & $42.9 \ddagger$ \\
\hline Mean (SD) FEV 1 pre-bd at visit 1 (\% pred) & $76.7(21.1)^{*} \dagger$ & $55.2(19.3)^{*}$ & $48.6(18.3) \dagger$ \\
\hline Mean (SD) FEV 1 post-bd at visit 1 (\% pred) & $98.3(16.6)^{*} \dagger$ & $84.2(19.2)^{*} \ddagger$ & $72.7(19.6) \dagger \ddagger$ \\
\hline Mean (SD) FEV 1 pre-bd at visit 2 (\% pred) & $93.6(9.9)^{*} \dagger$ & $55.5(15.3)^{*}$ & $54.7(19.0) \dagger$ \\
\hline Mean (SD) FEV 1 post-bd at visit 2 (\% pred) & $103.3(9.8)^{*} \dagger$ & $73.1(15.6)^{*} \ddagger$ & $60.0(19.1) \dagger \ddagger$ \\
\hline Mean (SD) FEV 1 reversibility at visit 1 (\% pred) & $21.6(13.8)^{*}$ & $29.0(11.8)^{*} \ddagger$ & $24.1(11.2) \ddagger$ \\
\hline Mean (SD) FEV 1 reversibility at visit 2 (\% pred) & $9.7(6.1)^{*} \dagger$ & $17.7(6.3)^{*} \ddagger^{+}$ & $5.3(3.0) \dagger \ddagger$ \\
\hline Mean (SD) FEV, \% IVC pre-bd at visit 1 (\%) & $63.2(15.4)^{*} \dagger$ & $48.2(14.3)^{*}$ & $46.3(15.4) \dagger$ \\
\hline Mean (SD) FEV 1 \% IVC post-bd at visit 1 (\%) & $77.2(11.6)^{*} \dagger$ & $67.7(13.6)^{*} \ddagger$ & $61.9(16.5) \dagger \ddagger$ \\
\hline Mean (SD) FEV $\%$ IVC pre-bd at visit $2(\%)$ & $71.6(7.3)^{*} \dagger$ & $52.0(11.0)^{*}$ & $54.8(14.3) \dagger$ \\
\hline Mean (SD) FEV $\%$ IVC post-bd at visit 2 (\%) & $75.4(6.9)^{*} \dagger$ & $59.1(11.2)^{*}$ & $55.5(15.4) \dagger$ \\
\hline Pulmonary medication use at visit $2(\%)$ & $41.9 * \dagger$ & $88.7^{*} \ddagger$ & $74.3 \dagger \neq$ \\
\hline Inhaled corticosteroid use at visit $2(\%)$ & $24.7^{*} \dagger$ & $72.2^{*} \ddagger$ & $51.4 \dagger \ddagger$ \\
\hline Oral corticosteroid use at visit $2(\%)$ & $1.1 * \dagger$ & $10.3^{*}$ & $17.1 \dagger$ \\
\hline Reduced Kco post-bd at visit $2(\%)$ & 21.1 & 20.3 & 36.0 \\
\hline
\end{tabular}

$\mathrm{BHR}=$ bronchial hyperresponsiveness; $\mathrm{FEV}=$ forced expiratory volume in 1 second; $\mathrm{KcO}=$ carbon monoxide transfer coefficient; bd=bronchodilator; $\mathrm{NAO}=\mathrm{FEV}$, pre-bd $\geqslant 80 \%$ predicted; $\mathrm{RAO}=\mathrm{FEV}$, pre-bd $<80 \%$ predicted and reversibility $\geqslant 9 \%$ predicted: $\mid \mathrm{AO}=\mathrm{FEV}$, pre-bd $<80 \%$ predicted and reversibility $<9 \%$ predicted. * $p<0.05, \mathrm{NAO} v \mathrm{RAO} ; \uparrow p<0.05$, NAO vIAO; $\ddagger p<0.05, \mathrm{RAO} v \mid \mathrm{AO}$. 


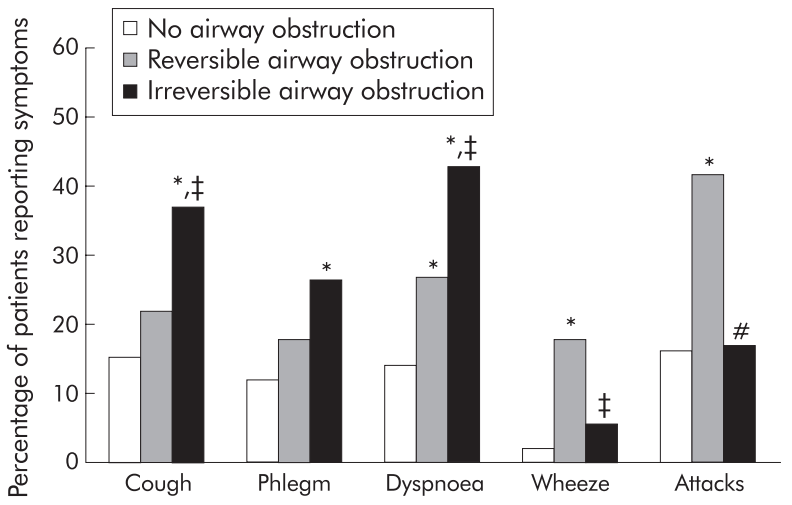

Figure 1 Percentage of subjects with respiratory symptoms at visit 2 . Subjects stratified by airway obstruction and reversibility $(n=225)$ No airway obstruction=prebronchodilator $\mathrm{FEV}, \geqslant 80 \%$ predicted; reversible airway obstruction=prebronchodilator $\mathrm{FEV}_{1}<80 \%$ predicted and reversibility $\geqslant 9 \%$ predicted; irreversible airway obstruction=prebronchodilator $\mathrm{FEV}_{1}<80 \%$ predicted and reversibility $<9 \%$ predicted; cough=cough daily for at least 3 months a year; phlegm=bringing up phlegm daily for at least 3 months a year; dyspnoea=shortness of breath when walking at regular pace; wheeze=wheeze on almost every day or night; attacks=one or more asthma attacks in the previous 3 years. ${ }^{*} p<0.05 v$ group with no airway obstruction; \#p<0.05 v group with reversible airway obstruction; $\ddagger p<0.10 v$ group with reversible airway obstruction

appropriate. These tests were also used to compare the characteristics of patients with a reduced Kco with those of patients with a normal Kco.

Multiple logistic regression analyses were performed on the presence of IAO and on the presence of a reduced Kco at visit 2. Only patients who had airway obstruction at visit 2 were included in the analysis of IAO. The parameters included for visit 1 were: prebronchodilator $\mathrm{FEV}_{1}$ (\% predicted), BHR as $\ln$ (slope), reversibility to a bronchodilator $(\Delta \mathrm{FEV}$, as $\% \mathrm{FEV}$, predicted), allergy status, duration of the untreated period (in years), and $\operatorname{sex}($ female $=0$, male $=1)$. For visit 2 the parameters included were age (in years), pack years of smoking, and the use of corticosteroids (oral and/or inhaled).

\section{RESULTS}

\section{Patient characteristics}

Between 1962 and 1970, 430 patients referred to Beatrixoord Hospital fitted the inclusion criteria. Of these, $202(47.0 \%)$ were not available for visit 2: 11 (2.6\%) had serious concomitant diseases, 26 (6.0\%) were reported to be dead, 64 (14.9\%) refused to participate in the study, 48 (11.2\%) could not be located, and 53 (12.3\%) were not approached because of time constraints. A total of 228 patients therefore participated in the study.

Table 1 shows that the non-participants were older, had a higher prevalence of smoking, and were less likely to be allergic at visit 1 than the participating subjects. There were no other significant differences between the participants and non-participants. The last column of table 1 shows the characteristics of the participants at the follow up visit. The median time to follow up was 26 years (range 21-33). At visit 2 bronchial hyperresponsiveness (BHR) was less severe and $15.7 \%$ of the patients no longer had BHR. The percentage of smokers fell from $36.8 \%$ to $26.8 \%$ during the follow up period and the percentage of allergic individuals fell from $94.3 \%$ to $82.5 \%$. Prebronchodilator FEV \% predicted values increased during the follow up period but postbronchodilator $\mathrm{FEV}_{1} \%$ predicted values fell. This is also reflected in a lower degree of reversibility at visit 2 .

\section{Airway obstruction and irreversible airway obstruction} At follow up (visit 2) 93 of the 228 participants (41.3\%) had no airway obstruction (NAO), 97 (43.1\%) had RAO, and 35 $(15.6 \%)$ had IAO (table 2 ). Three patients were excluded from the analysis because of missing lung function data at visit 2 . The patients with NAO were significantly younger than those with RAO or IAO and they had a shorter untreated period. At visit 2 the prevalence of allergy was significantly higher in the NAO group than in those with IAO. The FEV $1 \%$ predicted and $\mathrm{FEV}_{1} \%$ IVC in patients with NAO both before and after bronchodilator were significantly higher than in the other groups at both visits.

The postbronchodilator $\mathrm{FEV}_{1} \%$ predicted at both visits was significantly higher in the RAO group than in the IAO group, while the prebronchodilator $\mathrm{FEV}_{1} \%$ predicted did not differ between these groups. Reversibility at both visits was highest in the RAO group and differed significantly from the other groups. The RAO group also had the steepest slopes in the BHR test; at visit 1 the BHR slope in the RAO group was significantly steeper than in the NAO group while at visit 2 this slope was significantly steeper than in both the IAO and NAO groups. Patients with NAO used fewer asthma medications than the other groups at visit 2. Patients with IAO used fewer asthma medications at visit 2 than patients with RAO, which was primarily because fewer inhaled corticosteroids were used by the IAO group. There were no differences between the three groups in sex, age of onset of asthma, or smoking habits at both visits, nor in IgE levels and the proportion with reduced Kco at visit 2.

Figure 1 shows the percentage of patients reporting symptoms at visit 2 in the three groups. The NAO group reported
Table 3 Odds ratios (OR) and $95 \%$ confidence intervals $(95 \% \mathrm{Cl})$ of multiple logistic regression analyses on irreversible airway obstruction $(F E V$ prebronchodilator $<80 \%$ predicted and $\mathrm{FEV}$, reversibility $<9 \%$ predicted at visit 2 , only patients with prebronchodilator $\mathrm{FEV}_{1}<80 \%$ predicted included) and on a reduced postbronchodilator transfer coefficient ( $\mathrm{KCO},<80 \%$ predicted, all patients included)

\begin{tabular}{llllll}
\hline & \multicolumn{2}{l}{$\begin{array}{l}\text { Irreversible airway obstruction } \\
(\mathbf{n}=130)\end{array}$} & & \multicolumn{2}{l}{$\begin{array}{l}\text { Reduced postbronchodilator } \\
\text { Kco (n=162) }\end{array}$} \\
\cline { 2 - 3 } \cline { 5 - 6 } Outcome (no of cases in analysis) & OR & $95 \% \mathrm{Cl}$ & & OR & $95 \% \mathrm{Cl}$ \\
\hline Age at visit 2 & 0.96 & 0.91 to 1.02 & & 1.01 & 0.95 to 1.07 \\
Male sex & 0.88 & 0.33 to 2.32 & & $\mathbf{0 . 3 3}$ & 0.14 to 0.80 \\
Pack years at visit 2 & 1.01 & 0.98 to 1.04 & & $\mathbf{1 . 0 4}$ & 1.01 to 1.07 \\
FEV pre-bd at visit 1 (\% pred) & $\mathbf{0 . 9 5}$ & 0.92 to 0.98 & & 1.00 & 0.98 to 1.03 \\
In(slope BHR) at visit 1 & $\mathbf{0 . 6 4}$ & 0.41 to 1.00 & & 1.03 & 0.69 to 1.53 \\
Reversibility at visit 1 (\% pred) & $\mathbf{0 . 9 6}$ & 0.91 to 1.00 & & 1.00 & 0.97 to 1.04 \\
Allergy at visit 1 & 0.63 & 0.12 to 3.38 & & 2.29 & 0.38 to 13.72 \\
Untreated period & 1.05 & 1.00 to 1.10 & & 0.98 & 0.94 to 1.03 \\
Use of steroids at visit 2 & $\mathbf{0 . 2 2}$ & 0.07 to 0.64 & & 2.03 & 0.86 to 4.81 \\
\hline
\end{tabular}


Table 4 Characteristics of subjects stratified by reduced post-bronchodilator carbon monoxide transfer coefficient (KCO) at visit 2 ( $n=165)$

\begin{tabular}{|c|c|c|}
\hline & $\begin{array}{l}\text { No reduced Kco } \\
(n=127)\end{array}$ & $\begin{array}{l}\text { Reduced Kco } \\
(n=38) \dagger\end{array}$ \\
\hline Median (range) age at visit 1 (years) & $22(13-40)$ & $27(14-44)$ \\
\hline Sex ( $\%$ male) & $63.8^{*}$ & $44.7^{*}$ \\
\hline Median (range) age of onset of asthma (years) & $4(0-37)$ & $6(0-39)$ \\
\hline Median (range) untreated period (years) & $14(0-38)$ & $10.5(0-40)$ \\
\hline Smoking visit 1 , non/ex/current (\%) & $58.3 / 8.7 / 33.1$ * & $39.5 / 7.9 / 52.6 *$ \\
\hline Smoking visit 2 , non/ex/current (\%) & $43.3 / 32.3 / 24.4$ & $26.3 / 34.2 / 39.5$ \\
\hline Median (range) pack years of smoking at visit 2 & $2.5(0-80)^{*}$ & $8.0(0-58)^{*}$ \\
\hline$\geqslant 1$ positive skin test at visit $1(\%)$ & 93.7 & 94.7 \\
\hline$\geqslant 1$ positive skin test at visit $2(\%)$ & 82.7 & 78.9 \\
\hline Geometric mean (SD) lgE at visit 2 (IU) & $87.1(3.9)$ & $85.1(4.5)$ \\
\hline Geometric mean (SD) slope BHR at visit 1 & $6.0(3.4)$ & $7.2(3.7)$ \\
\hline Geometric mean (SD) slope BHR at visit 2 & $3.0(4.1)$ & $3.5(6.8)$ \\
\hline $\mathrm{BHR} \leqslant 4 \mathrm{mg} / \mathrm{ml}$ visit $1(\%)$ & 48.0 & 52.6 \\
\hline BHR $\leqslant 32 \mathrm{~m} / \mathrm{ml}$ visit $2(\%)$ & 85.0 & 72.7 \\
\hline $\mathrm{BHR} \leqslant 4 \mathrm{mg} / \mathrm{ml}$ visit $2(\%)$ & 42.5 & 54.5 \\
\hline Mean (SD) FEV , pre-bd at visit 1 (\% pred) & $65.4(23.1)$ & $63.2(24.0)$ \\
\hline Mean (SD) FEV 1 post-bd at visit 1 (\% pred) & $89.6(19.9)$ & $88.3(21.6)$ \\
\hline Mean (SD) FEV 1 pre-bd at visit 2 (\% pred) & $73.5(23.2)$ & $69.7(24.0)$ \\
\hline Mean (SD) FEV, post-bd at visit 2 (\% pred) & $86.2(21.5)$ & $80.6(23.5)$ \\
\hline Mean (SD) FEV 1 reversibility at visit 1 (\% pred) & $24.2(12.6)$ & $25.2(15.7)$ \\
\hline Mean (SD) FEV, reversibility at visit 2 (\% pred) & $12.7(7.9)$ & $10.9(8.5)$ \\
\hline Mean (SD) VC post-bd at visit 1 (\% pred) & $103.4(13.2)$ & $105.9(16.2)$ \\
\hline Mean (SD) VC post-bd at visit 2 (\% pred) & $102.9(14.6)$ & 107.5 (16.9) \\
\hline Median (range) TLC post-bd at visit 1 (\% pred) & $106.1(77.3-148.9)$ & $110.5(78.5-147.5)$ \\
\hline Median (range) TLC post-bd at visit 2 (\% pred) & $100.1(70.8-123.8)^{*}$ & $106.2(78.8-147.7)^{*}$ \\
\hline Median (range) RV post-bd at visit 1 (\% pred) & $114.2(53.7-228.5)^{*}$ & $134.9(71.8-219.5)^{*}$ \\
\hline Median (range) RV post-bd at visit 2 (\% pred) & $98.5(51.8-184.6)^{*}$ & $116.12(59.0-213.8)^{*}$ \\
\hline Pulmonary medication use at visit $2(\%)$ & 60.6 & 73.7 \\
\hline Inhaled corticosteroid use at visit $2(\%)$ & 42.5 & 57.9 \\
\hline Oral corticosteroid use at visit $2(\%)$ & 7.9 & 2.6 \\
\hline \multicolumn{3}{|c|}{$\begin{array}{l}\text { BHR=bronchial hyperresponsiveness; } F_{E V}=\text { forced expiratory volume in } 1 \text { second; } V C=\text { vital capacity; } \\
\mathrm{RV}=\text { residual volume; bd=bronchodilator. } \\
{ }^{*} \mathrm{p}<0.05 \text {. } \\
\text { †Reduced } \mathrm{KCO}=\mathrm{TLCO} / \mathrm{VA}_{\mathrm{A}}<80 \% \text { predicted. }\end{array}$} \\
\hline
\end{tabular}

fewer symptoms at visit 2, the RAO group reported more wheezing and current asthma attacks than the other groups, while the IAO group reported more symptoms of cough, phlegm and dyspnoea.

The results of the multiple logistic regression analyses are shown in table 3. The IAO group had significant ORs for prebronchodilator $\mathrm{FEV}_{1}$ (\% predicted) at visit 1 (OR 0.95, 95\% CI 0.92 to 0.98 ), $\ln$ (slope BHR) at visit $\mathrm{l}$ (OR $0.64,95 \%$ CI 0.41 to 1.00 ), reversibility (\% predicted) at visit 1 (OR $0.96,95 \% \mathrm{CI}$ 0.91 to 1.00 ), and the use of corticosteroids at visit 2 (OR 0.22 , 95\% CI 0.07 to 0.64 ). No significant effects were observed for age, sex, pack years of smoking at visit 2 , allergy at visit 1 , and the duration of the untreated period.

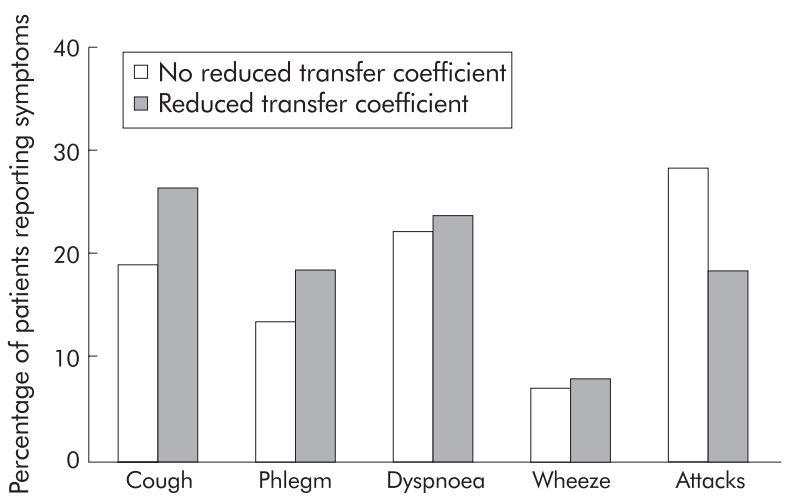

Figure 2 Percentage of subjects with respiratory symptoms at visit 2. Subjects stratified by reduced transfer coefficient (KCO (TLCO/VA) after bronchodilator $<80 \%$ predicted) at visit $2(n=165)$. Definition of symptoms as in fig 1 .

\section{Reduced transfer coefficient}

Because of technical problems in the procedures, postbronchodilator Kco could not be tested in four patients at visit 2. In another 59 patients Kco was not measured because of a change in the protocol. Thirty eight of 165 patients $(23.0 \%)$ had a reduced Kco after bronchodilation. Patients with reduced postbronchodilator Kco had a significantly higher total lung capacity (TLC) at visit 2 and a higher residual volume (RV) at both visits (table 4 ). At both visits the prevalence of smoking was higher in the group with a reduced $\mathrm{Kco}$, although the difference was only significant at visit 1 . Patients with a reduced Kco had smoked a greater number of pack years at visit 2 . Significantly more women had a Kco of $<80 \%$ predicted than men. There were no significant differences in age, age at onset of asthma, untreated period, allergic status at both visits, serum total IgE at visit 2, BHR at both visits, FEV, and VC at both visits, reversibility at both visits, and medication use at visit 2 . There were also no significant differences in the number of symptoms reported between the two groups (fig 2).

Multiple logistic regression analysis (table 3) showed that men had a lower risk of having a reduced Kco than women (OR for men 0.33 (95\% CI 0.14 to 0.80)). Patients who had smoked a higher number of pack years at visit 2 were more at risk of having a low Kco (OR 1.04, 95\% CI 1.01 to 1.07). No significant effects were observed for age, prebronchodilator $\mathrm{FEV}_{1}$ (\% predicted) at visit $1, \mathrm{BHR}$ at visit 1 , reversibility at visit 1 , allergy at visit 1 , the untreated period, and the use of corticosteroids at visit 2 .

An additional multiple logistic regression analysis including RV and TLC at visit 1 showed that these parameters were not independent risk factors for a low Kco at follow up, while the estimates of sex and smoking were unchanged. An analysis of the interaction between sex and smoking included in the model did not change the results. 


\section{DISCUSSION}

In a large cohort of 228 subjects with asthma studied extensively 21-33 years previously, approximately 16\% developed IAO, 43\% had retained their airway reversibility, and the remaining $41 \%$ had no evidence of airway obstruction. The development of IAO was associated with a lower FEV 1 (\% predicted), a lower level of BHR, less reversibility at initial testing, and with less use of corticosteroids at follow up; $23 \%$ had a reduced postbronchodilator Kco at visit 2. Female sex and a higher number of pack years were independent risk factors for having a reduced Kco. Only nine subjects ( $5 \%$ of all subjects) had both IAO and a reduced Kco at follow up, both features being compatible with a diagnosis of COPD.

\section{Airway obstruction and irreversible airway obstruction}

Subjects with NAO at follow up had less severe asthma at initial testing than those with either RAO or IAO- that is, better lung function and less severe BHR. At visit 2 these patients were less hyperresponsive, used less medication, and reported fewer symptoms (fig 1) than either the groups with RAO or IAO. At visit 2 the patients with RAO had the classic symptoms of asthma (reversible airway obstruction (by definition), BHR, symptoms of wheeze, and recent asthma attacks) more often than those in the IAO group. In contrast, the IAO group more often exhibited COPD-like symptoms (cough, phlegm and dyspnoea) but used less medication-particularly inhaled corticosteroids - than the RAO group.

Traditionally, asthma has been thought of as a disease characterised by RAO. However, it is acknowledged that asthma can evolve into IAO, probably as a result of airway remodelling caused by chronic inflammation of the airways. ${ }^{18}$ Our results suggest that an irreversible component of asthma is more likely to appear when $\mathrm{FEV}_{1}$ at first testing is low, when the severity of BHR is low, and when reversibility at first testing is low. The use of corticosteroids (inhaled and/or oral) may prevent the development of this irreversible component. Since $50 \%$ of the patients with IAO in our study did not use corticosteroids, it is possible that anti-inflammatory treatment might have prevented this irreversible component. In contrast, the observation that 89 of the 112 patients $(80 \%)$ treated with corticosteroids at visit 2 still had airway obstruction suggests that this treatment does not prevent a progressive decline in lung function in most patients with asthma. Another explanation may be that the introduction of inhaled corticosteroids was delayed too long after the start of the disease. Selroos et $\mathrm{al}^{19}$ suggested that early treatment of asthma with an inhaled steroid may prevent patients from developing chronic airway obstruction. Most of the patients in our study had asthma for more than 15 years at the time inhaled corticosteroids became available in The Netherlands (in 1974). This may have resulted in functional and structural changes in the airways due to ongoing inflammatory processes, thereby causing a faster deterioration in lung function and ultimately resulting in irreversible airway obstruction.

Ulrik and Backer ${ }^{11}$ performed the only other longitudinal study to examine early risk factors for the development of IAO in patients with asthma. In contrast to our results, they found that a higher degree of bronchodilator reversibility at enrolment was associated with IAO at follow up. This may be explained by a longer duration of follow up in our study, or by differences in the study group (Ulrik and Backer included only non-smokers and they were older than our study group), or by the way in which reversibility at enrolment was determined. Ulrik and Backer measured reversibility 15 minutes after inhalation of $5 \mathrm{mg}$ salbutamol while we measured it after an intramuscular injection of $25 \mathrm{mg}$ thiazinamium methylsulphate, a very potent anticholinergic drug with antihistamine properties. Although the bronchodilating capacity of thiazinamium methylsulphate in asthma is without doubt, ${ }^{20}{ }^{21}$ the comparability of the bronchodilating response to intramuscular thiazinamium sulphate and inhaled salbutamol has not formally been tested; this response may not be comparable both because of the type of drug and the route of administration.

Other studies have shown that a longer duration of asthma and more severe disease are associated with IAO. ${ }^{12-14}$ In the present study the duration of asthma at visit 2 was not associated with the development of an irreversible component of the airway obstruction. This can be explained by the fact that the duration of asthma is strongly associated with the level of lung function at visit 1 . Excluding $\mathrm{FEV}_{1}$ at visit 1 from the analysis resulted in a significant effect of the duration of asthma on the presence of IAO at visit 2. However, in our study the duration of asthma at visit 1 was equivalent to the time since onset of asthma and the start of treatment. The duration of asthma therefore also reflects the delay in treatment. We suggest that the development of IAO is caused by a longer delay in treatment rather than by a longer duration of the disease.

The severity of BHR at first testing seemed to be protective against the development of IAO. This could be caused by airway remodelling. Researchers are not sure about the consequences of airway remodelling on the level of BHR, but it has been suggested that either BHR gets worse or that airway remodelling protects against exaggerated airway narrowing. ${ }^{22}$ The findings that less BHR and less reversibility at first testing are both associated with the development of IAO suggest that airway remodelling had already started 26 years ago. Because both BHR and reversibility are highly correlated with $\mathrm{FEV}_{1}$, we repeated the analysis without $\mathrm{FEV}_{1}$. This resulted in a lower estimate of both BHR and reversibility in childhood but, although they still had the same sign, these estimates were no longer significant. We therefore have to be cautious in interpreting these estimates. Only a few studies have investigated the effect of BHR in childhood on the level of reversibility or the level of lung function in adulthood, and the results are conflicting with some studies reporting no association ${ }^{23} 24$ and others reporting a positive association.

\section{Reduced transfer coefficient}

Lynch and colleagues ${ }^{25}$ have shown that asthma patients who smoke more frequently have evidence of emphysema, as assessed by high resolution CT scanning, than patients with asthma who do not smoke. We used a reduced Kco as a marker which is highly correlated with the presence of emphysema on a CT scan. Comparison of the group with a reduced post-bronchodilator Kco and the group with a (near) normal Kco supported the findings of Lynch et al. ${ }^{25}$ The group with a reduced Kco included individuals with longer smoking histories. This group had a significantly higher RV and TLC at visit l, which suggests that emphysematous changes could have started early in the course of obstructive lung disease. At that time there were already more smokers among the patients with a reduced Kco than in those in whom Kco was not reduced $(52.6 \% \quad v 33.1 \%)$. A striking finding was that significantly more women had a TLCO/VA of $<80 \%$ predicted at visit 2 . This was not caused by a greater susceptibility of women to the effects of smoking, as suggested by $\mathrm{Xu}$ et al, ${ }^{26}$ because the interaction between smoking and sex was not significant.

Our results suggest that patients with more severe asthma have a higher risk of developing IAO. Patients with asthma who had smoked more pack years were at a higher risk of developing subsequent reductions in Kco. In this group with airway obstruction a low $\mathrm{FEV}_{1}$, less severe BHR, and lower bronchodilator reversibility at initial testing is associated with a higher risk of developing an irreversible component of airway obstruction 26 years later. Although the start of anti-inflammatory treatment in this population was late, it seems that the development of an irreversible component of airway obstruction can be prevented or at least delayed by this medication, even at this stage of asthma. Signs of emphysema 
(low Kco) were found in a small subset of patients, particularly in those with a higher number of pack years and in women. Neither low $\mathrm{FEV}_{1}$ at initial testing nor the use of corticosteroids were associated with a reduced Kco at follow up. Finally, patients with IAO were more likely to report cough, dyspnoea, and phlegm and those with RAO reported more wheeze and asthma attacks. The number of symptoms in the groups with a high or low Kco were comparable.

Although both IAO and reduced Kco are characteristics of COPD, they seem to represent two distinct groups with regard to symptomatology, aetiology, and approach to treatment in this population of patients with asthma.

\section{ACKNOWLEDGEMENTS}

This study was supported by a grant from the Dutch Asthma Foundation. The authors also acknowledge financial support from the "Astma Bestrijding" and "De Kock Stichting" Foundations, and thank Mr E Gankema for his technical support.

\section{Authors' affiliations}

J M Vonk, J P Schouten, Department of Epidemiology and Statistics, University of Groningen, The Netherlands

H Jongepier, Beatrixoord Hospital, Haren, The Netherlands C I M Panhuysen, Boston University Schools of Medicine and Public Health, Boston, MA, USA

E R Bleecker, University of Maryland, Baltimore, Maryland, USA D S Postma, Department of Pulmonology, University Hospital Groningen, The Netherlands

\section{REFERENCES}

1 Gerritsen J, Koëter GH, Postma DS, et al. Prognosis of asthma from childhood to adulthood. Am Rev Respir Dis 1989;140:1325-30.

2 Panhuysen CIM, Vonk JM, Koëter GH, et al. Adult patients may outgrow their asthma. A 25-year follow-up study. Am J Respir Crit Care Med 1997; 155:1267-72.

3 Roorda RJ, Gerritsen J, Aalderen van WMC, et al. Risk factors for the persistence of respiratory symptoms in childhood asthma. Am Rev Respir Dis 1993; 148: 1490-5

4 Gooijer de A, Brand PLP, Gerritsen J, et al. Changes in respiratory symptoms and airway hyperresponsiveness after 27 years in a population-based sample of school children. Eur Respir $J$ 1993;6:848-54

5 Boulet LP, Turcotte H, Brochu A. Persistence of airway obstruction and hyperresponsiveness in subjects with asthma remission. Chest 1994:105:1024-31.

6 Roorda RJ. Childhood asthma: outcome after 20 years. Pediatr Pulmonol 2001;Suppl 18:99-102
7 Lange P, Parner J, Vestbo J, et al. A 15-year follow-up study of ventilatory function in adults with asthma. $N$ Engl J Med 1998;339: 1194-2000

8 Peat JK, Woolcock AJ, Cullen K. Rate of decline of lung function in subjects with asthma. Eur J Respir Dis 1987;70:171-9.

9 Ulrik CS, Lange P. Decline of lung function in adults with bronchial asthma. Am J Respir Crit Care Med 1994;150:629-34.

10 Backman KS, Greenberger PA, Patterson R. Airways obstruction in patients with long-term asthma consistent with 'irreversible asthma'. Chest 1997; 1 12:1234-40.

11 Ulrik CS, Backer V. Nonreversible airflow obstruction in life-long nonsmokers with moderate to severe asthma. Eur Respir J 1999; 14:892-6.

12 Hudon C, Turcotte $H$, Laviolette $M$, et al. Characteristics of bronchial asthma with incomplete reversibility of airflow obstruction. Ann Allergy Asthma Immunol 1997:78:195-202.

13 Brown PJ, Greville HW, Finucane KE. Asthma and irreversible airflow obstruction. Thorax 1984;39:131-6.

14 Finucane KE, Greville HW, Brown PJ. Irreversible airflow obstruction. Evolution in asthma. Med J Aust 1985;142:602-4.

15 Sakai F, Gamsu G, Im JG, et al. Pulmonary function abnormalities in patients with CT-determined emphysema. J Comput Assist Tomogr 1987;11:963-8.

16 American Thoracic Society. Definitions and classification of chronic bronchitis, asthma, and pulmonary emphysema. Am Rev Respir Dis 1962;85:762-85

17 American Thoracic Society. Standards for the diagnosis and care of patients with chronic obstructive pulmonary disease (COPD) and asthma Am Rev Respir Dis 1987;136:225-44.

18 Elias JA. Airway remodeling in asthma. Unanswered questions. Am J Respir Crit Care Med 2000;161:S168-71.

19 Selroos O, Pietinalho A, Löfroos A-B, et al. Effect of early vs. late intervention with inhaled corticosteroids in asthma. Chest 1995; 108: 1228-34.

20 Booy-Noord H, Orie NGM, Cate ten $\mathrm{HJ}$, et al. The influence of various drugs on the vital capacity of asthmatics. Int Arch Allergy Appl Immunol 1957; 10:321-41.

21 Bork van EL. Thiazinamium methylsulfaat. Een onderzoek naar de farmacodynamiek en de klinische toepassing bij chronisch gegeneraliseerde obstructieve longaandoeningen. Thesis Rijksuniversiteit Groningen, The Netherlands, 1978

22 Vignola AM, Kips J, Bousquet J. Tissue remodeling as a feature of persistent asthma. J Allergy Clin Immunol 2000;105:1041-53.

23 Roorda RJ, Gerritsen J, Aalderen van WMC, et al. Follow-up of asthma from childhood to adulthood: influence of potential childhood risk factors on the outcome of pulmonary function and bronchial responsiveness in adulthood. J Allergy Clin Immunol 1994;93:575-84.

24 Grol MH, Gerritsen J, Vonk JM, et al. Risk factors for growth and decline of lung function in asthmatic individuals up to age 42 years. A 30-year follow-up study. Am J Respir Crit Care Med 1999;160:1830-7.

25 Lynch DA, Newell JD, Tschomper BA, et al. Uncomplicated asthma in adults: comparison of CT appearance of the lungs in asthmatic and healthy subjects. Radiology 1993;188:829-33.

26 Xu X, Weiss ST, Rijcken B, et al. Smoking, changes in smoking habits, and rate of decline in $\mathrm{FEV}_{1}$ : new insight into gender differences. Eur Respir J 1994;7:1056-61. 